\title{
Sustainability Between "Witness" and Concrete Policies
}

\author{
Federico Testa
}

ENEA, Sede Legale Lungotevere Thaon Di Revel, Roma 76 00196, Italy

Corresponding Author Email: presidenza@enea.it

https://doi.org/10.18280/ti-ijes.640101

Received: 25 April 2019

Accepted: 10 June 2019

\section{Keywords:}

sustainability, energy system, electricity, renewable sources, smart grids

\begin{abstract}
Sustainability is a very fashionable word, especially in its environmental sense and rightly captures greater attention, because "connects" us directly to the issue in its broader vision and leads to reflect about human activity impacts on the environment in which we live. But, as regard to the electricity production, it implies problems such as programmability of the offer, transmission and dispatching system, saturation of the networks, inequality of electricity prices.

It must be taken into account that we still have to work on the technological aspect and to the issue related to energy storage, with respect to which, in the face of undoubted progress in terms of costs, heavy questions remain about durability, density and end of life. The target could be a more than correct self-production aspiration, through renewable sources articulated on the territory, in order to ensure a "closeness" between producers and users, by starting with concrete experiences.
\end{abstract}

\section{INTRODUCTION}

Sustainability is very "fashionable" right now. Certainly the underlying reasons are profound and entirely acceptable: beyond the more or less catastrophic readings, and the permanence of reductionist theses that tend to insert phenomena in the "natural millennial course", it is clear to all the observation of a change in action in the climate of our planet and of the consequences that this entails in actual and even more prospective human life. The search to identify more precisely the problem, in relation to some of the most discussed issues in our country, becomes useful. Sustainability, in its dominant sense, that is environmental, rightly captures greater attention, because "connects" us directly to the issue in its broader vision and leads to reflect about human activity impacts on the environment in which we live. Nevertheless, this dimension runs the risk of being not only extremely partial, but also of exposing to an apparent consensus that at the end eventually produces poor practical results, beyond the one - certainly important - of an increased awareness. In other words: in front of a representative audience about the importance of environmental issue, surely you would get an almost unanimous consent, but.... then it is necessary to take the next step, that is to transform the consent to a declaration of principle (witness) into something more concrete, therefore in political and technical proposals of real change. A great help towards this direction comes from the concept of technical/engineering sustainability, namely from the real viability of the solutions that can be identified thanks to the available knowledge. Some examples can help you to understand even better [1-2].

\section{SUSTAINABILITY OF AN ENERGY SYSTEM}

If we talk about electricity production, it is clear that the use of sun, wind and tides is "environmentally" more sustainable than traditional sources, mainly fossil ones. So, all of us can only agree with this perspective. But talking about sustainability of an energy system means - moreover - arise problems such as programmability of the offer and characteristic constraints of the transmission and dispatching system, typical of a "good" that is not normally storable like electricity, among which:

- the request for an instantaneous and continuous balancing between the quantities of energy fed into the grid and those taken from the grid, net of transport and distribution losses;

- the maintenance of the energy frequency and voltage in the network within a precise range, with great harm to the installation's safety;

- the need for energy flows on each individual power line not to exceed the maximum permissible transit limits on the power line itself.

All that in presence of a network that maintains bottlenecks and which in turn must be subdivided into zones, not easily permeable between them.

The necessary balance between injections and withdrawals at every moment and in every node of the network is guaranteed by the automatic regulation and control systems of the production units (so-called primary and secondary reserve), which increase or reduce the input into the network in order to compensate any unbalance on the network itself; however, not all production units (for example the majority of photovoltaic and wind power plants) are able to provide this service. The subject that carries out this activity (in Italy Terna) actively takes part - by sending orders to the tertiary reserve units to switch on, increase or reduce the power supplied - when the operating margins of the automatic regulation systems are lower than the safety standards in order to reintegrate them.

It is essential to take into account the fact that only about 1000 of production units with power above a certain level 
(normally $10 \mathrm{MW}$ ) and connected to the transmission network are considered by Terna as points of supply offer (so-called "relevant production plants"); more than 550,000 minor production units, typically from renewable sources and normally connected to the distribution network (so-called "distributed generation"), are instead considered by Terna as a load reduction, or as a decrease in demand at a point of offer in sampling; obviously when the production from renewable sources exceeds the loads connected to the same sampling point, a negative sampling program is obtained.

The uncertainty of these sources leads to an increase in the error of forecasting the residual load from real-time balances and, therefore, to an increase in the frequency and power regulation requirements, both in increase (reserve to increase) and in decrease (reserve to go down).

To this it must be added that the increased renewable production, reducing the portion of load satisfied by units of thermoelectric production with adjustment capacity, makes even more complex the constitution of the margins of reserves needed to ensure the balance in real time of network electricity. These difficulties are further exacerbated for effect of deficiencies infrastructure (poor meshing of network and thermoelectric systems of old generation with scarce capacity of adjustment) of the zones in which the sources not programmable are available.

\section{THE RISK OF NETWORKS SATURATION}

Finally, the saturation of the networks is not an only virtual problem.

In fact, already today, there are really saturated electric networks and, therefore, not able to evacuate all the electrical production introduced in them. The problem appears above all along some Apennine ridges characterized by the presence of numerous plants (mostly wind plants) and with limited or absent loads.

To solve this problem, it is necessary to develop electricity grids and, jointly, to evaluate the construction of storage systems (such as pumping systems) that allow to exploit at best the available network.

The weight of generation distributed from renewable sources is relatively modest in terms of energy production on an annual basis, around $10 \%$, but significant both in terms of power (around 20,000 MW out of a total of 120,000 MW) and, above all, in relation to demand, which it is on average 37,000 MW and fluctuates between a minimum of $21,000 \mathrm{MW}$ and a peak of 54,000 MW.

The main consequences of this system set-up are both of a technical and an economic nature for the proper functioning of the market. In fact, as regards to the technical aspect, the system security has undoubtedly been reduced: the significant presence of non-programmable and intermittent sources entails an insufficient level of reserves and this can affect, in particular situations, even the security level. For example, when the production level of photovoltaic and wind power plants meets the demand in the same area (typically in the summer with low demand, in daylight hours and on windy days), Terna, in order to guarantee system security has not only to "call" however programmable thermoelectric plants, even if the market is theoretically in equilibrium, but too exposed to the "discontinuity" risk, but also to stop a certain amount of renewable plants. This situation occurred in the last few summers in a few hundred hours and will become more and more frequent with the increase in renewable production. The greater is the intervention of Terna in the imminence of delivery time (i.e. the moment in which the plants must execute the instructions of the Operator), the greater is the difficulty of managing the system in a safe way.

\section{THE EVOLUTION OF SMART GRIDS}

All this involves a rethinking of the management methods of the distribution networks, which must pass from "passive" to "active". This direction of evolution is identified, at international level, with the term smart grid, implying strongly innovative structures and operating methods which, in addition to maintaining a high level of safety and reliability of the entire system, are also able to cope with the numerous problems related to the management of distributed generation.

But this way, which we are going to cross, is all under construction ... and therefore the option of "all renewable, all with sun and wind", although very fascinating... it must certainly be undertaken with the awareness of the forward steps that we still have to make from the technological point of view. Last but not least, the issue related to energy storage, with respect to which, in the face of undoubted progress in terms of costs, heavy questions remain about durability, density and end of life.

Likewise we can reason in terms of circular economy, another very "fashionable" matter of these times...Also in this case the basic idea is fascinating and convincing: we close the cycles, we transform - for example with regard to industrial production - what is the waste of a company in the raw material of another one, with the benefit of avoiding the disposal costs for one and lowering supply costs for the other one... in the moment in which you must pass from the enunciation to the practice... things get complicated not a little... (which, it is confirmed, does not mean that these things are not going to be done, but it means on the contrary, to be able to acquire the awareness of the steps necessary to make them really...And don't just "witness" them). Building such a mechanism in fact schematically involves

- to build databases with incoming and outgoing flows for local businesses, with a level of detail that allows to analyze them in order to understand if what appears to be the result of my production process can be modified according to its use as input in another production process;

- to verify that the input of my process can be modified in order to use the output of another process;

- to consider everything on a territorial "mobile" base, in the sense that the potential distance between output source and input destination is not fixed, but variable depending on the economic value of the material and therefore of convenience to support the related transport costs, which evidently increase as the route increases.

It can be done? Certainly, but it is necessary to start with concrete experiences that go beyond niche ones, already realized (in Italy mainly by ENEA), in order to be able to generalize step by step the modus operandi... Otherwise it remains a slogan... Fascinating but a slogan.

The next step is that which leads to economic sustainability, that is to the "validation" of what is identified through the "lens" of the economy. Also, in this case: the thing can be trivialized ("but this is clear, what we talk about!!!") or, on the contrary, exploited ("it concerns the destiny of the planet, no economic readings!"). The most correct approach is probably 
the one that, recognizing the strategic value of the topic, does not forget the fundamental principle according to which the economy deals with the search for the best allocation of scarce resources, and which therefore rightly inserts this type of analysis in the overall evaluation sheet of a project. Here also some concrete examples.

With the change in the supply structure on the electricity market, the share of plants that are dying in a competitive regime has been reduced: in fact, renewable sources in the market enjoy dispatching priority (guaranteed by European directives) and therefore act as "price takers". Essentially, the market solution mechanism based on the marginal price (all plants are remunerated at the price of the most expensive plant that is selected in the Day-Ahead Market) allows renewable sources to offer at zero price and be remunerated at the price of the most expensive thermoelectric plant without taking part in the market; therefore competition only occurs between thermoelectric plants. Furthermore, with a significant proportion of renewable sources, the outcome of the MGP is more and more often not executable because the plants selected on the basis of economic merit do not guarantee a sufficient level of reserves which, as already mentioned, cannot be supplied by photovoltaic or wind power plants; subsequent markets have therefore assumed the improper function of "correcting" the outcome of the MGP to ensure system security. Of course, any change is onerous. Finally, there is a lack of equity between the remuneration of thermoelectric plants and the remuneration of renewable sources. The MGP does not distinguish and valorizes in the same way the energy offered by thermoelectric plants and the one offered by non-programmable renewable plants, which is not only more uncertain and therefore requires the availability of reserves, but cannot offer reserve services. This inequity is what generates the request for a "capacity payment" in favour of thermoelectric plants motivated by the fact that it is the very existence of such plants that allows the operation of the electricity system.

\section{IS ITALIAN ENERGY SYSTEM COMPATIBLE WITH THE LIFE OF CITIZENS?}

All this leads us to what we can call "economic sustainability" of the Italian energy system: this structure of the sources, the system of incentives for renewables, the costs of maintaining a balanced (and therefore safe) system are compatible with the life of the Italian citizens and businesses?

In 2012, electricity prices for Italian domestic consumers were below the average prices charged in the European Union for the first two consumption classes (including lower annual consumption of $1,000 \mathrm{kWh}$ and up to $2,500 \mathrm{kWh}$ ), both net and both gross of taxes and charges, while they were higher for the remaining consumption classes. In this case the comparison does not give particularly problematic results, although it is important to underline how the greater use of the electric carrier compared to more traditional ones and the spread of new technologies could also expose families to the risk of "sliding" towards consumption classes with higher prices than those practiced on average in the European Union.

Electricity prices for Italian companies, however, in 2012 resulted higher than the European average for all consumer classes. In particular for the consumption class 500-2,000 $\mathrm{MWh}$, one of the most representative for our market, prices were higher than the EU average of $37 \%$ (it was $27 \%$ in 2011) for net prices and $47 \%$ (it was 34\% in 2011) for gross prices. The increase in the gross price for this consumption class between 2012 and 2011 was among the highest in Europe, above $16 \%$ against an EU average of $5.5 \%$ [2]. This caused a significant penalization for our companies, especially small and medium-sized ones, which do not enjoy any form of reduction in the cost of energy, which are instead reserved for so-called energy-intensive businesses.

So, some questions about the (economic) sustainability of the system are absolutely correct. But not only. In recent years, the progressive development of renewable sources in Italy has been pursued with an incentive mechanism for the energy bill and not for general taxation. If this, on one hand, had the positive effect of an increasing production from renewable sources in our country, on the other hand it has meant that Italian bills, as we have seen, despite the decrease in raw material costs in recent years, do not have suffered significant reductions and indeed, facing with the rise of the oil cost, they are likely to increase significantly also because, in the meantime, on the energy bill they ended up weighing additional costs such as those relating to:

- upkeep the system in balance: the most widespread renewable sources are discontinuous - not programmable and therefore they need to have a form of "reserve" that makes safe the supply even in the presence of adverse climatic factors. Waiting for significant progress in the field of accumulators, this happens by keeping some traditional power stations in stand-by, ready to intervene, which must therefore be paid and whose cost is actually added together;

- energy consumers: there are companies for which energy is one of the main factors of production. For them, higher energy costs $=$ loss of competitiveness. As European law rightly prohibits state aid, if you reduce the cost for someone this higher cost comes to be discharged on all other users, thus increasing their bills;

- reform of the tariff system: in the past, as consumption groups grew, indirect costs increased proportionately, today in view of the possible increase in electricity consumption, many people push so that it is no longer so, thus increasing the component that is charged on small consumers;

- all of this ended up heavily affect the dynamics of the energy bill, also because the overall impact of all the individual measurements was underestimated, which measures taken individually could have a sense ....

The result is that the Italian "system" is somewhat loaded by choices/dynamics that greatly reduce the decision maker's margins of action, which has to find new balance points while taking into account choices already made and which heavily weigh on the bills. One among all: at the moment you think about self-consumption mechanisms, you need to know that if you expand the audience of those who do not contribute to pay the "system charges" generically understood, those charges will fall pro rata on the other consumers, with the consequence of further aggravating the already high costs. Not otherwise, with more general reference to the push towards the electric carrier, when the consumer is still paying on the bill the investments related to the transmission and distribution networks of the gas, it is necessary to pay attention to the temporal scan of the new investments - necessary - in transmission and, above all, taking into account the characteristics of the electricity distribution of many of our urban centers.

How to intervene? First of all, by reviewing and "tempering" some of the taken measures and then: 
- evaluating the possibility of transferring part of the previous incentive measures to general taxation, thus transforming them from a sort of "hidden taxation" into an explicit national policy in favour of the environment and sustainability;

- carefully reconsidering the reductions for energyconsumptive companies, limiting them only to ones that actually operate to an important extent on the international market;

- introducing the elements of gradualness necessary to avoid that the push to investments aimed at increasing the spread of the electric carrier goes to add to the costs already present in the bill, further increasing the amounts.

Again, therefore, a more than correct self-production aspiration, through renewable sources (environmental sustainability) articulated on the territory, in order to ensure a "closeness" between producers and users (a chance of economic democracy?), is faced with a wider problem, which runs the risk of precluding or making inaccessible the prospect that one intends to cross.

\section{THE PROSPECT OF SUSTAINABLE MOBILITY}

Similarly, and lastly, the prospect of sustainable mobility (very briefly). Also, in this case, it is difficult to find an interlocutor opposed to the spread of electric mobility in the cities: those who live in the Po valley have a good idea of what the stagnation of humidity, fine dust, smog means especially in the winter months. On the subject there are still some technical-engineering problems, which we often hear about: the need for the energy that powers the cars to be produced from renewable sources (if not we have only de-localized the problem), the duration of the charge of the batteries (while great progress is being made regarding costs), the end of life of the accumulators. Not so much attention has been given, over time, to the issue of the infrastructure network necessary for recharging: in other words, if I want to recharge ever more powerful batteries in a short time (Tesla charges to $150 \mathrm{~kW}$, the future Porsche to $350 \mathrm{~kW}$ ) I must have the availability of a lot of energy in a decentralized way, where I need it. Thirty apartments today normally absorb $150 \mathrm{~kW}$ ( $3 \mathrm{~kW}$ each one), seventy apartments require $350 \mathrm{~kW}$, and so on... This means very important investments on the distribution networks, and problems that are not insignificant on the balance of the system at local level (my TV goes off because the neighbor is recharging the car), which can enormously amplify if the balance is to be found at the level of the condominium or neighborhood (decentralized self-production). Certainly, the investments can and must be done, but with such a program to minimize the impact on the bills, because as we have seen, Italy is already at the top of the list.... But perhaps we could also think of alternative charging systems: the current fuel supply network could be structured (an opportunity to finally address the issue of the anomalous number of our distributor system) in such a way as to supply in that location, through stationary batteries powered in medium voltage, the recharge service in a few minutes, through qualified and duly equipped workers (large electrical power in a short time $=$ greater risk of accidents). Wouldn't it make sense, before making significant investments (which are always and, in any case, bore by the community), to make an accurate assessment of the various possible systems so as to minimize the economic impacts? Here too ... environmental sustainability, but also technical engineering, but then also economic; at least if you really want to do things and make them possible. If it is only a witness, of course, there is no problem...

\section{CONCLUSIONS}

In summary: the destiny of the planet and of the human race that inhabits it is a topic of primary importance, which first of all deserves great reflections and consequent choices of an adequate level. If the growth of attention in recent years is certainly a positive sign, it is necessary to avoid that this ends up bringing with it the risk of an easy trivialization of the problems and the relative solutions. In this sense the deeper understanding of the various meanings of the term sustainability and their concrete implications in order to achieve a greater balance between man and the environment can certainly help to identify the concrete political choices that can lead to a true sustainability of human action.

\section{ACKNOWLEDGMENT}

The editor would like to thank Dr. Tiziana Cardinale, $\mathrm{PhD}$, for the translation of the speech held by Prof. Testa in Matera on 13th June during the 4th AIGE/IIETA International Conference and 13th AIGE 2019 Conference on "Energy Conversion, Management, Recovery, Saving, Storage and Renewable Systems".

\section{REFERENCES}

[1] Federico Testa is full professor of Management at the University of Verona. Since March 2016 he is President of ENEA (Italian National Agency for New Technologies, Energy and Sustainable Economic Development)

[2] Source: AEEG, 2013 Annual Report. 